\title{
Data Mining in Product Cycle Prediction of Company Mergers
}

\author{
Dr. Sandeep Dwarkanath Pande \\ Ph. D. (Computer Science and Engineering), KLEF (NAAC A++ Accredited), Guntur, AP, India, \\ Sr. Assistant Professor, School of Computer Engineering and Technology, \\ MIT, Academy of Engineering, Alandi, Pune
}

\begin{tabular}{|l|l|}
\hline $\begin{array}{l}\text { Article History } \\
\text { Article Submission } \\
19 \text { April } 2021 \\
\text { Revised Submission } \\
14 \text { June 2021 }\end{array}$ & $\begin{array}{l}\text { Abstract } \\
\text { Article Accepted } \\
13 \text { July 2021 } \\
\text { Article Published } \\
30 \text { September 2021 } \\
\text { is associated with a quest to achieve or attain and retain competitive advantages. With } \\
\text { firms have ended up embracing business internationalization to stretch beyond local } \\
\text { and regional borders within which they are based. With these efforts associated with } \\
\text { improved company performances, Wal-Mart has been unexceptional. The effort to } \\
\text { retain a competitive advantage and superior brand image across the world has been } \\
\text { evidenced by its recent merger with Massmart, a South African company that owns } \\
\text { brands such as Builder's Warehouse, Makro, and Game. It is also worth highlighting } \\
\text { that Massmart is South Africa's second largest distributor of consumer goods and } \\
\text { remains the largest retailer dealing in basic foods, liquor and home improvement } \\
\text { equipment, and general merchandise. This paper examines the merger between Wal- } \\
\text { Mart and Massmart, focusing on issues such as the international market analysis of the } \\
\text { retail industry, aspects of product category and demand size, and competition analysis. } \\
\text { In so doing, resultant recommendations might give an insight into current trends in } \\
\text { business marketing strategies that embrace mergers, as well as lay an opportunity for } \\
\text { improvement in the Walmart-Massmart merger and others at the intra-industry and } \\
\text { inter-industry level. } \\
\text { Keywords: Data Mining, Decision Support Systems, Product Management }\end{array}$ \\
\hline
\end{tabular}

\section{Introduction}

WalMart Stores, Inc. is a multinational retail operator and based in America. The company operates chains of grocery stores, discount department stores, and hypermarkets. According to Ferrell \& Hartline (2008), the firm is headquartered in Arkansas' Bentonville region and was founded by Sam Walton. With its history dating back to 1962, latest statistics indicate that as of October 31, 2016, Wal-Mart had established 11,593 clubs and stores in 28 countries. In a 2016 list by Fortune Global 500, it has been affirmed that Wal-Mart remains the largest private employer in the world and the largest firm by revenue. Specifically, the company has 2.2 million employees and remains a family-owned business belonging to the Walton family. Some of the products produced by the company include poultry, meat, pharmacy, pet shop, photo-processing labs, fresh seafood, dairy products, frozen foods, and baked goods. Other products are found in hair and nail salons, cellular phone stores, fast food outlets, local bank branches, and video rental stores. Overall, the company deals in major retail goods and services falling in broad categories of basic foods, liquor and home improvement equipment, and general merchandise.

South Africa was among the few regions that stood on their feet in the wake of a financial meltdown that made most of the global zones to stagger, especially when the new millennium's first decade approached the end (Gitman \& McDaniel, 2009). According to Capon and Hulbert (2011), this state of stability in South Africa was 
attributed to its prudent monetary and fiscal policies. For instance, the country has a desirable score in terms of political stability and a blend of an established manufacturing base, research and development capabilities, well developed regulatory systems, abundant natural resources, and a well-capitalized banking system (Ferrell \& Hartline, 2008). As such, the World Bank has ranked the country as one that belongs to the upper-middle income groups and comes second in the African context after Nigeria. Economic diversity has also been reported in South Africa. Major sectors shaping the country's GDP include personal services at 5.9 percent, government services at 17.6 percent, business, real estate and finance services at 20.7 percent, communication, storage and transport at nine percent, and, accommodation, catering, motor trade, retail and wholesale at 14.6 percent. Others include construction at 3.9 percent, electricity and water at 2.6 percent, manufacturing at 13.3 percent, mining at 10 percent, and agriculture at 2.2 percent. From this outcome, capital or income availability among most of the citizens in Africa's second largest economy poses a high likelihood. It is further notable that South Africa has designed a National Development Plan 2030 that focuses on major business-related strategic goals. The goals entail improving and investing in infrastructure while supporting industries that include agriculture and mining, export diversification, strengthened links towards a fast-paced economic growth, and reform enactment with the intention of lowering the costs of doing business. Other goals include constraint reduction in a variety of sectors, moving to a climate friendly and more efficient system of production, and encouraging innovation and entrepreneurship (Gitman \& McDaniel, 2009). Thus, these goals blend with the promising state of income availability to translate into a positive or supportive environment at Wal-Mart's perceived destination, South Africa.

\section{Methodology}

At the country levels, South Africa's promising economic arena matches that of the U.S., especially when the issue of stability was reported during the global financial meltdown that emerged towards the end of the first decade of the new millennium. When Geert Hofstede's cultural dimensions are examined, the two countries reveal significant commonalities. These outcomes are summarized in the following figure.

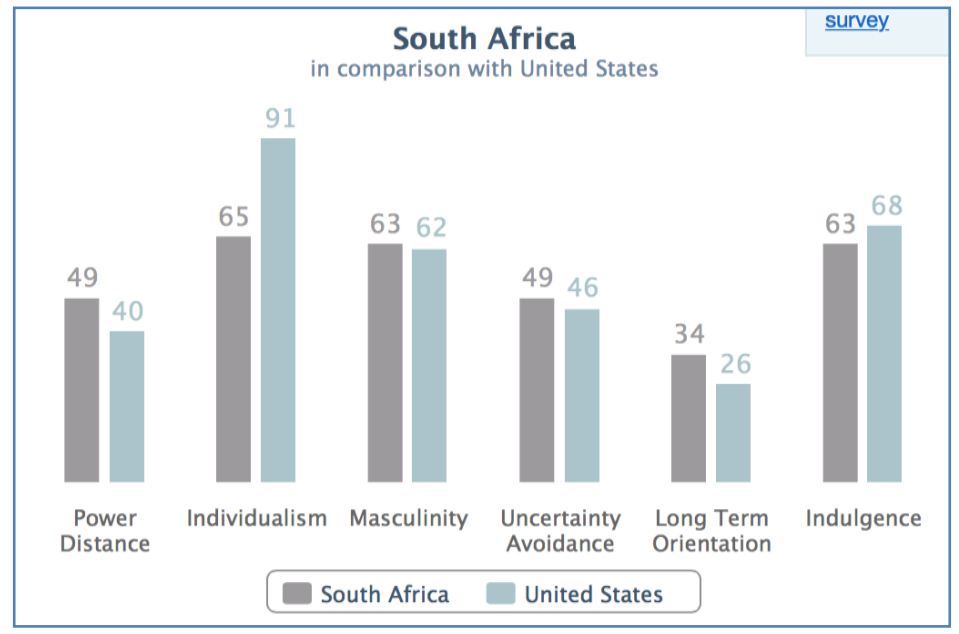

Figure 1. Comparison of South Africa and United States

Regarding the match and alignment of the involved companies' products and services, Wal-Mart deals in broad categories of basic foods, liquor and home improvement equipment, and general merchandise while Massmart also deals in consumer goods, the wholesale of basic foods, liquor and home improvement equipment, and general merchandise (Capon \& Hulbert, 2011). The eventuality is that the nature of operation in the two states predicts a state of product and service complementariness. It is also worth noting that Massmart, as of July 31, 2016, operated 
12 stores in other Sub-Saharan countries while 404 stores were located in the country. The primary entry strategy in this case involves a merger. Indeed, the approach is appropriate due to similarities in cultural dimensions and the nature of goods and services supplied, a coincidence suggesting that challenges such as employee resistance to change and, differences in corporate and national cultures between the U.S. and South Africa and, Wal-Mart and Massmart (respectively) might be limited. Overall, the merger between Wal-Mart and Massmart is timely and is predicted to foster sustainable development due to the strategic goals that South Africa seeks to accomplish by 2013.

\section{Results and Discussion}

In the current state of global retail industry, one of the issues to watch concerns margin erosion in the wake of rising volumes whose boost has arisen from high purchasing powers. Notably, high purchasing power is a result of cheap oil (Ferrell \& Hartline, 2008). On the other hand, it has been predicted that inflation is likely to pick up and exceed the 2016 expectations (China $+1.8 \%$ and USA $+1.7 \%$ ). Therefore, the merger and acquisition activities' tide is unlikely to abate and the trend could trigger more business repositioning and group restructuring (Wal-Mart, 2011). It has also been predicted that there is a possible arrival of additional disruptive players and technologies that could force the existing product and service providers to embrace dynamic approaches while seeking to keep abreast and maintain their global competitive advantages (Gitman \& McDaniel, 2009). With rising consumer spending coming in the wake of low oil prices, it was expected that revenue growth in the retail industry would be significantly higher but in 2015, a mere $+2 \%$ increase was documented (Capon \& Hulbert, 2011). The stalled progress in the retail sector has been attributed to fierce battles for market supremacy between online and traditional players.

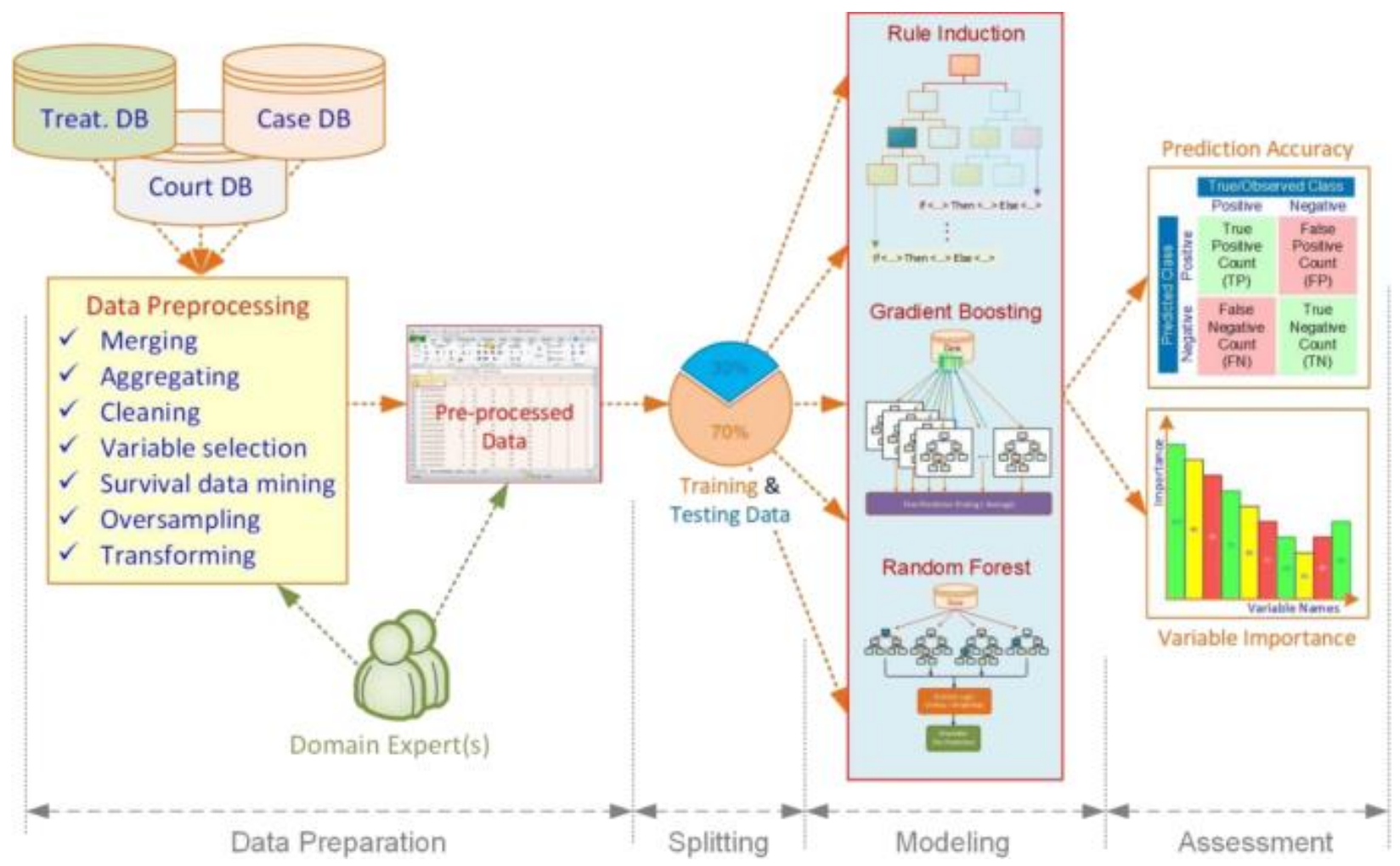

Figure 2. Data Flow Processing

In the current business arena, dramatic and rapid changes characterize the retail landscape. For example, consumers have become more far informed and yielded rapid product choice proliferations. Furthermore, barriers to market 
entry have been reduced and yielded fragmented retail landscapes due to the arrival of new small players. Thus, market demand has expanded and geographic proximity transcended by online marketplaces (Ferrell \& Hartline, 2008). As such, a remapped and unbundled retail value chain is emergent. With support, sales and designs less strongly linked, niche and small entrants have been drawn from various flexible options towards activity execution. Thus, consumers have been converted by traditional retailers into agents to navigate product sizes (Wal-Mart, 2011; Kanning and Bergmann, 2009).

Product life cycles fall in stages based on the products' state of revenue generation. The stages include introduction, growth, maturity, and the decline stage. Given the nature of products at Wal-Mart and Massmart, it can be inferred that they belong to or are approaching the maturity stage because brand awareness is strong. The eventuality is that continued sales growth is experienced but more competitors emerge with similar products. Thus, companies operating at the maturity stage seek to extend the product life cycle top defend their market share; remaining attractive to loyal customers (Gitman \& McDaniel, 2009).

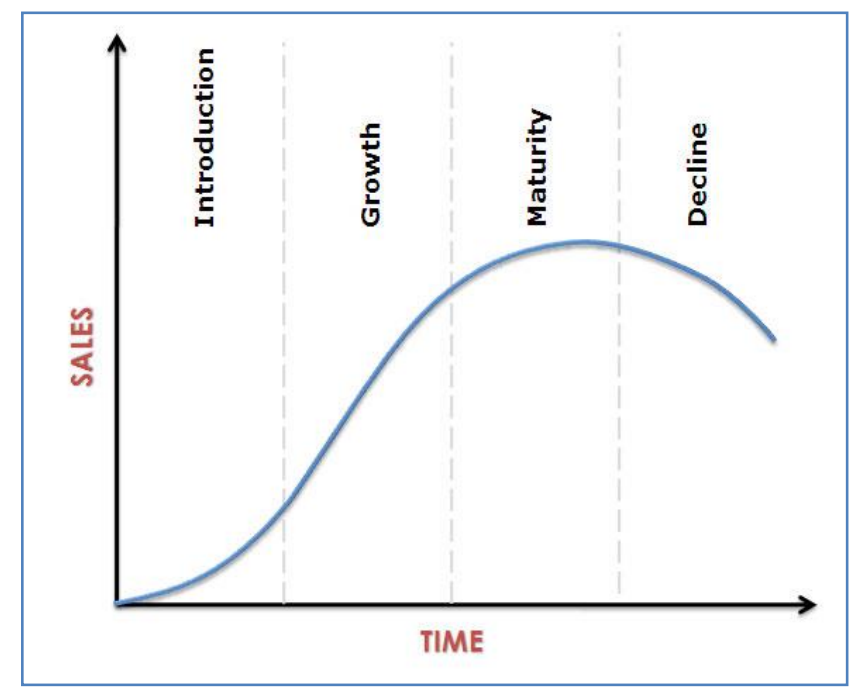

Figure 3. Flow of Sales with time

The structure of the retail industry keeps changing due to changes in consumer behavior, new technological developments, increased size of retail stores, and diversified retail formats. For example, starters have on the other hand, other players entail regionally-targeted or family-run stores but multinational conglomerates such as Sears and Wal-Mart have, increasingly, taken over this market. As such, larger retailers have set up huge distribution or supply chains and proceeded to incorporate wide scale marketing plans, financing pacts, and inventory management systems (Capon \& Hulbert, 2011). From these mixed outcomes, it can be inferred that the retail industry does not have a fixed or rigid structure, and that the nature of a retail operator's structure is dependent on issues such as size and type of ownership. The central factor is that all these players are in a continuous quest to differentiate themselves from competition.

In the retail industry, major competitors to Wal-Mart include Target Corporation, Amazon, Coulomb Technologies, Best Buy, and Apple Inc. Others include Netflix, Aldi, Sears Holdings Corporation, Google, Dollarama, Harris Teeter, and Kroger (Ferrell \& Hartline, 2008). Therefore, sets of lackluster performance at WalMart could be linked to external factors; led by stiff competition. A major effort that these competitors have made involves e-commerce in which online shopping continues to dominate the retail marketplace and an expansion of consumer bases. Thus, Wal-Mart has had to keep developing and embracing new technologies to keep abreast. It is further notable that globalization has led to the emergence of frequent efforts geared towards achieving business internationalization. The eventuality is that most of the competing firms in the retail industry have ended up 
establishing themselves as multinational corporations whose aim is not only to distribute products at the regional and local levels but also stretch to participate in business activities on the international scene (Wal-Mart, 2011). The implication for Wal-Mart is that stiff competition threatens its competitive advantage and global brand image.

From the analysis, there is a need for Wal-Mart to prioritize, based on the strengths, to exploit existing opportunities that are found in the global marketplace. In addition, company threats and weaknesses ought to be secondary priorities. The eventuality is that the product quality standards and human resource management standards could be improved in a quest to achieve the trickledown effect of improved company performance. Similarly, there is a need for Wal-Mart to continually expand its business with the intention of exploiting economic opportunities that the emerging or developing markets pose. Lastly, the strengths of high supply chain efficiency, global supply chain, and global organization size should be used as bases for supporting aggressive global expansions while seeking entry into foreign markets; including South Africa.

Given the presence of a large population in South Africa, there is a need for Wal-Mart to launch sensitization campaigns regarding benefits that the consumer group might enjoy, should it buy its products. To achieve this objective, communication platforms such as print media, television and social media should be utilized to reach out to as many customers in the Sub-Saharan region as possible. It is further notable that product marketing could be achieved by conducting pilot studies spearheaded by the research and development team to understand tastes and preferences of different community groups in South Africa, upon which an effective product differentiation strategy could be designed and implemented to cement the company's presence. Lastly, Wal-Mart could use Massmart as an entry channel through which the existing user groups could be reached and sensitized about the issue or nature of the company's brand image; a step that might yield fruitful product marketing outcomes.

\section{Conclusion}

In summary, Wal-Mart's merger with South Africa's Massmart is timely. For example, the economy of South Africa depicts the presence of demand due to income availability. However, Wal-Mart's merger should be dominated by the use of Massmart's company representatives as an entry strategy to reach out to customers and sensitize them about the better experience that might result from the merger and their eventual decision to purchase products supplied by the newly merged firms. Indeed, it is projected that the merger's effort geared towards embracing technology is central to success due to the capacity of platforms such as online media to allow customer groups to interact with the products and services supplied by the new firm. Overall, the merger is likely to succeed but aspects of transactional, transitional and transformative leadership towards effective change management should be prioritized to avoid a possible backlash and potential resistance to change among employees at Wal-Mart and Massmart, as the merger involves two firms in the same (retail) industry but exhibiting variations in corporate and national cultures.

\section{References}

[1] Capon, N. \& Hulbert, J. M. (2011). Marketing Management in the 21st Century. Upper Saddle River, New Jersey: Prentice-Hall.

[2] Ferrell, O. C. \& Hartline, M. D. (2008). Marketing strategy. Mason, OH: Thomson South Western.

[3] Gitman, L. J. \& McDaniel, C. D. (2009). The future of business: The essentials. Mason, OH: Southwestern Cengage Learning.

[4] Kanning, U. P. and Bergmann, N. (2009). Predictors of Customer Satisfaction: Testing the Classical Paradigms. Managing Service Quality, 19(4), 377-390

[5] Wal-Mart. (2011). Annual Report: Building the Next Generation Wal-Mart. Retrieved on December 13, 2016 from http://walmartstores.com/sites/annualreport/2011/financials/Walmart_2011_Annual_Report.pdf 